\title{
EDITORIAL
}

\section{Home at last? Early discharge for acute pulmonary embolism}

\author{
V.F. Tapson* and M.V. Huisman ${ }^{\#}$
}


ntithrombotic treatment for acute deep vein thrombosis (DVT) or pulmonary embolism (PE) should consist of a therapeutic dose of low molecular weight heparin (LMWH) for $\geqslant 5$ days, followed by a vitamin $\mathrm{K}$ antagonist for $\geqslant 3$ months. LMWH has simplified the initial management of DVT because it is at least as effective and safe as unfractionated heparin and can be administered in fixed subcutaneous doses without laboratory monitoring [1]. These advantages over standard, unfractionated heparin allow the majority of patients with DVT to be treated at home without being admitted to hospital, improve the quality of life and reduce healthcare costs $[2,3]$. While a recent meta-analysis concluded that $\mathrm{LMWH}$ is at least as effective and safe as unfractionated heparin for the initial treatment of nonmassive PE [4], the question of starting treatment for PE in the outpatient setting has been less satisfactorily addressed. While DVT and PE are clearly manifestations of one pathophysiological process, it cannot be assumed that they can always be treated the same. Patients treated for PE appear to be almost four times as likely (1.5 versus $0.4 \%$ ) to die of recurrent venous thromboembolism (VTE) in the following year than patients treated for DVT [5]. While outpatient PE therapy for carefully selected patients may already be the standard of care [6], for certain experienced physicians, many practitioners are less secure with this approach. Based on data from DAvIES et al. [7] in the current issue of the European Respiratory Journal, one may move closer to a comfort level.

Previous trials have suggested the feasibility of early discharge or entire outpatient therapy for acute PE, but have had limitations including study size, retrospective data collection and/or lack of randomisation [8-14]. Certain large randomised outpatient DVT trials have included PE patients, but again, small numbers have precluded firm conclusions [15].

However, several previous studies have given more reason to believe that outpatient therapy is feasible $[6,16]$. Kovacs et al. [16] published results from a nonrandomised but prospective

\footnotetext{
*Dept of Pulmonary and Critical Care Medicine, Duke University Medical Center, Durham, NC, USA ${ }^{\text {\#}}$ Section of Vascular Medicine, Dept of General Internal Medicine-Endocrinology, Leiden University Medical Center, Leiden, The Netherlands.

STATEMENT OF INTEREST: A statement of interest for V.F. Tapson can be found at www.erj.ersjournals.com/misc/statements.shtml

CORRESPONDENCE: M.V. Huisman, Section of Vascular Medicine, Dept of General Internal Medicine-Endocrinology, Leiden University Medical Center, Leiden, The Netherlands. Fax: 31 715248140. E-mail: m.v.huisman@lumc.nl
}

cohort of PE patients managed in the outpatient setting, clearly outlining inclusion and exclusion criteria. Obvious indications for admission included haemodynamic instability, but any patient requiring oxygen also had to be admitted. Other reasons for hospitalisation included: another medical indication; severe pain requiring parenteral analgesia; or high risk of bleeding. Of the $108 \mathrm{PE}$ patients treated in the outpatient setting, 81 were managed exclusively as outpatients, with an overall symptomatic recurrence rate of VTE of six (5.6\%) out of 108 and a major bleeding rate of only two (1.9\%) out of 108 . There were four deaths, none of which were due to PE or major bleeding. The recurrence rates demonstrated were about the same as in large randomised trials examining predominantly or only DVT in the outpatient setting $[15,17,18]$; the major bleeding rates were as low or lower. While nonrandomised, this study set the stage for a closer look.

WELLS et al. [14] have already examined the feasibility of outpatient PE therapy as part of a large outpatient DVT therapy effort. In the latter study, 34 patients with acute PE were treated as outpatients. In 2005, WELLS et al. [6] published a prospective outpatient study in which patients were randomised to one of two LMWH preparations for outpatient therapy of acute DVT and/or PE (but not randomised to inpatient versus outpatient therapy). Of the 505 randomised patients, 90 had acute PE. PE patients were specifically excluded if they had associated hypotension, hypoxaemia on room air, or severe pain requiring intravenous narcotics. In the 90 PE patients, only two had a recurrent thromboembolic event. There were no major haemorrhages. Three patients with PE died of other causes during the 90-day follow-up. Again, these results are at least as good as the overall outcome event rates in patients with DVT only, further suggesting the appropriateness of outpatient therapy for acute PE.

DAVIES et al. [7] report an outpatient treatment study in patients with acute PE. The design of the study included an initial exploratory phase in which physicians were asked to indicate whether 225 patients with acute PE, all treated as in-patients, could be discharged early. For each patient deemed unsuitable for outpatient management, the clinician recorded and clearly outlined the rationale for exclusion. The same exclusion criteria were then validated in the subsequent phase of the study, in which 157 patients with confirmed PE were enrolled and follow-up was available in all but one of them. In these patients, who were predominantly treated in the outpatient setting, the outcomes were remarkably good. No VTE or major bleeding events occurred. There were only three 
non-PE-related deaths, all of which occurred after the acute treatment phase. Of the 124 patients who completed a satisfaction score, $81(65 \%)$ gave a score of 10 , indicating maximum satisfaction. Furthermore, 144 (97\%) out of 149 patients indicated that they would prefer outpatient therapy if they had a subsequent PE. It is worth noting that the study was not entirely in the outpatient treatment setting but was an early discharge study. Patients stayed in the hospital for the median 1 day required for objective testing for $\mathrm{PE}$, and $\mathrm{LMWH}$ treatment was given to a proportion of patients during daily hospital visits. While DAvIES et al. [7] conclude that outpatient treatment of PE is safe and effective in their population, the study does have limitations. First, and most importantly, patients were not randomised. It is known that outcome outside the clinical trial setting is often rosier than in carefully controlled studies. In addition, the selection process of study patients in the second phase of the study was not well described and it is impossible to tell exactly how patients entered the outpatient cohort. A reflection of this selection process may be the very low $1.9 \%$ death rate during the 3month follow-up, suggesting that a highly selective group of outpatients had been chosen to be treated out of the hospital, given that a 3-month mortality of $7-8 \%$ has been reported for patients with PE in recent population-based studies [19]. Nonetheless, the assumed highly selected patients who met the criteria to be treated as outpatients in phase 2 did have an excellent outcome [7]. Careful triage of patients is crucial in the success of any home-treatment programme of patients with acute VTE and only transparent reporting of inclusion and exclusion criteria from carefully designed studies will lead to a higher acceptance of outpatient therapy for acute, stable PE [2].

Prognostic considerations in PE are important to both stratify patients for more aggressive (e.g. thrombolytic) therapy as well as to assist in determining which patients are the best candidates for outpatient therapy for acute PE. Thus, another drawback in the selection of patients in the study by DAVIES et al. [7] is the absence of any risk stratification on the basis of echocardiography, biomarker measurements (including troponin or brain natriuretic peptide (BNP)) or use of any prognosticating tool. The presence of right ventricular dysfunction at echocardiography or computed tomography at presentation or hospital discharge [20,21], as well as increased troponin or BNP plasma concentrations, have all been demonstrated to be associated with a poorer outcome in patients with haemodynamically stable PE. However, neither of these markers have been prospectively validated in a management study; therefore, the predictive value of these methods is still uncertain. More recently, heart-type fatty acid-binding protein has been shown to be a promising early indicator of right ventricular injury and dysfunction, even when the right ventricle is normal as assessed by echocardiography [22].

Prognostic models have been developed and validated and may help determine patients who were at risk for poor outcomes. The Geneva score has been developed and subsequently validated [23] and requires an arterial blood gas measurement as well as ultrasound of the legs. AUJESKY et al. [24] recently developed and validated a PE severity index (PESI) in patients with proven PE, utilising 11 routinely available clinical parameters and providing physicians with a bedside PE risk assessment tool, without need for imaging or laboratory tests. This model appeared to accurately identify patients with PE at low risk of fatal and nonfatal medical outcomes. The test characteristics of the Geneva model and the Aujesky model for predicting 30-day outcomes (mortality, VTE recurrences and major bleeding) have recently been compared [25]. The discriminatory power of both prognostic models was compared, with the PESI quantifying the prognosis of patients with PE better than the Geneva score. The PESI classified fewer patients into the low-risk strata than in previous studies. However, this score was still able to identify $\sim 25 \%$ of patients who had very low risk of an adverse event. It proved very useful in identifying patients who can undergo initial acute PE therapy with good outcomes.

The study by DAVIES et al. [7] reinforces the fact that selected patients can be quickly discharged and safely treated in the outpatient setting, but a clearer identification of selection criteria would offer the potential for more widespread acceptance of this approach. Basic considerations, such as haemodynamic stability and lack of oxygen requirement, are intuitive; perhaps applying a previously validated prognostic score $[23,24]$ would facilitate a more standardised approach. Large randomised studies comparing outpatient to in-hospital treatment of patients with pulmonary embolism would be useful, and the use of prognostic models might offer greater guaranteed safety for this approach [25]. Medical therapy continues to move in the outpatient direction when possible, with the goals of cost savings and patient satisfaction. A reduction in iatrogenic problems and nosocomial disease are potential benefits. Nonetheless, a means by which the approach to outpatient therapy can be standardised further is crucial.

\section{REFERENCES}

1 Gould MK, Dembitzer AD, Doyle RL, Hastie TJ, Garber AM. Low-molecular-weight heparins compared with unfractionated heparin for treatment of acute deep venous thrombosis. A meta-analysis of randomized, controlled trials. Ann Intern Med 1999; 130: 800-809.

2 Eikelboom J, Baker R. Routine home treatment of deepvein thrombosis. BMJ 2001; 322: 1192-1193.

3 Gould MK, Dembitzer AD, Sanders GD, Garber AM. Lowmolecular-weight heparins compared with unfractionated heparin for treatment of acute deep venous thrombosis. A cost-effectiveness analysis. Ann Intern Med 1999; 130: 789-799.

4 Quinlan D, McQuillan A, Eikelboom JW. Low-molecularweight heparin compared with intravenous unfractionated heparin for treatment of pulmonary embolism: a metaanalysis of randomized, controlled trials. Ann Intern Med 2004; 140: 175-183.

5 Douketis JD, Kearon C, Bates S, Duku EK, Ginsberg JS. Risk of fatal pulmonary embolism in patients with treated venous thromboembolism. JAMA 1998; 279: 458-462.

6 Wells PS, Anderson DR, Rodger MA, et al. A randomized trial comparing 2 low-molecular-weight heparins for the outpatient treatment of deep vein thrombosis and pulmonary embolism. Arch Intern Med 2005; 165: 733-738.

7 Davies CWH, Wimperis J, Green ES, et al. Early discharge of patients with pulmonary embolism: a two-phase observational study. Eur Respir J 2007; 30: 708-714. 
8 Dager WE, King JH, Branch JM, et al. Tinzaparin in outpatients with pulmonary embolism or deep vein thrombosis. Ann Pharmacother 2005; 39: 1182-1187.

9 Lim AY, Parr DG, Stableforth DE, Fellows M, Fontaine R, Fegan CD. Early discharge and home supervision of patients with pulmonary embolism treated with lowmolecular weight heparin. Eur J Intern Med 2003; 14: 89-93.

10 Ong BS, Karr MA, Chan DKY, Frankel A, Shen Q. Management of pulmonary embolism in the home. Med J Aust 2005; 183: 239-242.

11 Siragusa S, Arcara C, Malato A, et al. Home therapy for deep vein thrombosis and pulmonary embolism in cancer patients. Ann Oncol 2005; 16: Suppl. 4, iv136-iv139.

12 Beer JH, Burger M, Gretener S, Bernard-Bagattini S, Bounameaux $H$. Outpatient treatment of pulmonary embolism is feasible and safe in a substantial proportion of patients. J Thromb Haemost 2003; 1: 186-187.

13 Olsson CG, Bitzén U, Olsson B, et al. Outpatient tinzaparin therapy in pulmonary embolism quantified with ventilation/perfusion scintigraphy. Med Sci Monit 2006; 12: PI9-PI13.

14 Wells PS, Kovacs MJ, Bormanis J, et al. Expanding eligibility for outpatient treatment of deep venous thrombosis and pulmonary embolism with low-molecularweight heparin: a comparison of patient self-injection with homecare injection. Arch Intern Med 1998; 158: 1809-1812.

15 The Columbus Investigators. Low-molecular-weight heparin in the treatment of patients with venous thromboembolism. N Engl J Med 1997; 337: 657-662.

16 Kovacs MJ, Anderson D, Morrow B, Gray L, Touchie D, Wells PS. Outpatient treatment of pulmonary embolism with dalteparin. Thromb Haemost 2000; 83: 209-211.

17 Levine M, Gent M, Hirsh J, et al. A comparison of lowmolecular-weight heparin administered primarily at home with unfractionated heparin administered in the hospital for proximal deep-vein thrombosis. N Engl J Med 1996; 334: 677-681.

18 Koopman MM, Prandoni P, Piovella F, et al. Treatment of venous thrombosis with intravenous unfractionated heparin administered in the hospital as compared with subcutaneous LMWH administered at home. The Tasman Study Group. N Engl J Med 1996; 334: 682-687.

19 Nijkeuter M, Söhne M, Tick LW, et al. The natural course of hemodynamically stable pulmonary embolism: clinical outcome and risk factors in a large prospective cohort study. Chest 2007; 131: 517-523.

20 Grifoni S, Vanni S, Magazzini S, et al. Association of persistent right ventricular dysfunction at hospital discharge after acute pulmonary embolism with recurrent thromboembolic events. Arch Intern Med 2006; 166: 2151-2156.

21 van der Meer RW, Pattynama PM, van Strijen MJ, et al. Right ventricular dysfunction and pulmonary obstruction index at helical CT: prediction of clinical outcome during 3-month follow-up in patients with acute pulmonary embolism. Radiology 2005; 235: 798-803.

22 Puls M, Dellas C, Lankeit M, et al. Heart-type fatty acidbinding protein permits early risk stratification of pulmonary embolism. Eur Heart J 2007; 28: 224-229.

23 Nendaz MR, Bandelier P, Aujesky D, et al. Validation of a risk score identifying patients with acute pulmonary embolism, who are at low risk of clinical adverse outcome. Thromb Haemost 2004; 91: 1232-1236.

24 Aujesky D, Roy PM, Le Manach CP, et al. Validation of a model to predict adverse outcomes in patients with pulmonary embolism. Eur Heart J 2006; 27: 476-481.

25 Jiménez D, Yusen RD, Otero R, et al. Prognostic models for selecting patients with acute pulmonary embolism for initial outpatient therapy. Chest 2007; 132: 24-30. 